\title{
Genetic parameters for reproductive losses estimated from in-line milk progesterone profiles in Swedish dairy cattle
}

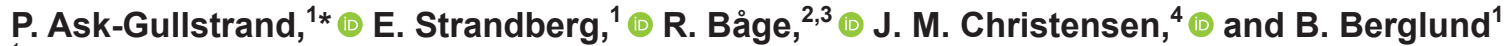 \\ ${ }^{1}$ Department of Animal Breeding and Genetics, Swedish University of Agricultural Sciences, PO Box 7023, SE-750 07 Uppsala, Sweden \\ ${ }^{2}$ Department of Clinical Sciences, Swedish University of Agricultural Sciences, PO Box 7054, SE-750 07 Uppsala, Sweden \\ ${ }^{3}$ Växa Sverige, PO Box 30204, SE-104 25 Stockholm, Sweden \\ ${ }^{4}$ Lattec, Slangerupsgade 69, 3400 Hillerod, Denmark
}

\section{ABSTRACT}

This study assessed the extent of reproductive losses and associated genetic parameters in dairy cattle, using in-line milk progesterone records for 14 Swedish herds collected by DeLaval's Herd Navigator. A total of 330,071 progesterone samples were linked to 10,219 inseminations (AI) from 5,238 lactations in 1,457 Swedish Red and 1,847 Swedish Holstein cows. Pregnancy loss traits were defined as early embryonic loss (1-24 d after $\mathrm{AI})$, late embryonic loss (25-41 d after AI), fetal loss (42 d after AI until calving), and total pregnancy loss (from d 1 after AI until calving). The following classical fertility traits were also analyzed: interval from calving to first service, interval from calving to last service, interval between first and last service, calving interval, and number of inseminations per service period. Least squares means with standard error $(\mathrm{LSM} \pm \mathrm{SE})$, heritabilities, and genetic correlations were estimated in a mixed linear model. Fixed effects included breed, parity $(1,2, \geq 3)$, estrus cycle number when the AI took place, and a linear regression on 305 -d milk yield. Herd by year and season of AI, cow, and permanent environmental effect were considered random effects. Extensive (approximately 45\%) early embryonic loss was found, but with no difference between the breeds. Swedish Red was superior to Swedish Holstein in the remaining pregnancy loss traits with, respectively: late embryonic loss of $6.1 \pm 1.2 \%$ compared with $13.3 \pm$ $1.1 \%$, fetal loss of $7.0 \pm 1.2 \%$ compared with $12.3 \pm$ $1.2 \%$, and total pregnancy loss of $54.4 \pm 1.4 \%$ compared with $60.6 \pm 1.4 \%$. Swedish Red also had shorter calving to first service and calving to last service than Swedish Holstein. Estimated heritability was 0.03, 0.06, and 0.02 for early embryonic, late embryonic, and total pregnancy loss, respectively. Milk yield was moderately

Received July 30, 2020.

Accepted October 2, 2020.

*Corresponding author: patricia.gullstrand@slu.se genetically correlated with both early and late embryonic loss (0.52 and 0.39 , respectively). The pregnancy loss traits were also correlated with several classical fertility traits $(-0.46$ to 0.92$)$. In conclusion, Swedish Red cows had lower reproductive loss during late embryonic stage, fetal stage, and in total, and better fertility than Swedish Holstein cows. The heritability estimates for pregnancy loss traits were of the same order of magnitude as previously reported for classical fertility traits. These findings could be valuable in work to determine genetic variation in reproductive loss and its potential usefulness as an alternative fertility trait to be considered in genetic or genomic evaluations.

Key words: progesterone, pregnancy loss, heritability, genetic correlation

\section{INTRODUCTION}

Low fertility in dairy cattle manifests itself as a long AI period requiring additional inseminations per successful pregnancy, indicating substantial reproductive losses and resulting in a long calving interval (Tenghe et al., 2015; Nyman et al., 2018). Consequently, impaired fertility is one of the main reasons for culling in Swedish dairy herds, accounting for approximately $18 \%$ of cows culled in 2019 (Växa Sverige, 2020). This has major economic consequences for the herd owner (Santos et al., 2004; Diskin et al., 2012).

Different approaches have been suggested to predict reproductive loss in cattle. Ultrasonography, palpation, and analysis of substances associated with pregnancy found in blood and milk (e.g., progesterone, P4) are predominantly used today (Bruinjé and Ambrose, 2019; Ealy and Seekford, 2019). A more precise diagnosis of reproductive status can be obtained with higher sampling frequency (Blavy et al., 2018; Bruinjé and Ambrose, 2019). Milk samples are preferable, because the methodology is noninvasive and does not require additional handling of live animals, which is laborious and time-consuming (Bruinjé and Ambrose, 2019). 
The Herd Navigator system (HN; DeLaval International, Tumba, Sweden) is a management tool designed to monitor reproduction and health status in dairy herds. It automatically samples and analyzes (in-line) milk P4 at certain time intervals based on a biomodel described by Friggens and Chagunda (2005) (DeLaval International, 2011; Bruinjé et al., 2017; Bruinjé and Ambrose, 2019). The system minimizes the effect of the environment and management decisions by alerting the herd owner to key elements in production, such as resumption of cyclicity after calving, estrus detection, optimal time for insemination, likelihood of conception, and reproductive issues (DeLaval International, 2011; Bruinjé et al., 2017).

Previous studies have mainly focused on how inline $\mathrm{P} 4$ records can be used to assess and improve the resumption of normal cyclicity after calving, and if endocrine fertility traits derived from $\mathrm{P} 4$ can be used in addition to, or instead of, classical fertility traits to genetically improve this aspect of dairy cattle fertility (e.g., Tenghe et al., 2015, 2018; Tarekegn et al., 2019). Because sampling continues for approximately $60 \mathrm{~d}$ after the last recorded insemination in $\mathrm{HN}$, the system also offers an opportunity to estimate early reproductive losses.

Various definitions of reproductive loss can be found in the literature. Most follow the categories established by the Committee on Bovine Reproductive Nomenclature (1972) to standardize reproductive losses, where embryonic loss is pregnancy loss from $1 \mathrm{~d}$ until approximately $45 \mathrm{~d}$ after insemination and fetal loss is loss from approximately $45 \mathrm{~d}$ after insemination until expected calving. Embryonic losses are further subdivided into early or late, where pregnancy loss during the first $24 \mathrm{~d}$ after insemination is considered early, and loss between 25 and 42 to $50 \mathrm{~d}$ is considered late embryonic loss (e.g., Santos et al., 2004). Several studies have reported an effect of parity but, on average, 30 to $50 \%$ of inseminations end in early embryonic loss, 10 to $15 \%$ in late embryonic loss, and around $10 \%$ in fetal loss (Bruinjé et al., 2017; Nyman et al., 2018). Previous studies have also reported differences in reproductive outcome depending on the P4 concentration before, during, and after insemination (Båge et al., 2002; Båge, 2003).

To the best of our knowledge, reproductive losses based on $\mathrm{P} 4$ have only been analyzed previously using manually sampled P4 data (Nyman et al., 2018) or HN data on small sample sizes (Bruinjé et al., 2017; van Binsbergen et al., 2019). Furthermore, few estimates of genetic parameters for reproductive loss based on P4 data have been reported. If genetic variation exists in these traits, this information could prove useful in routine genetic evaluation to improve fertility and reduce reproductive losses in dairy cattle. Therefore, the aim of this study was to use in-line milk $\mathrm{P} 4$ records to assess the extent of reproductive losses and to estimate genetic parameters for pregnancy loss traits in Swedish Red (SR) and Swedish Holstein (SH) cows.

\section{MATERIALS AND METHODS}

In-line milk P4 and milk yield (MY) records for 14 Swedish HN herds in the period 2015 to 2019 were obtained. The HN system automatically samples and analyzes milk P4 at frequencies specified by the system's biomodel, which is based on calculations by Friggens and Chagunda (2005). The biomodel is described in detail by Bruinjé et al. (2017, 2019) and validated by Bruinjé and Ambrose (2019). In total, our data set covered 407,794 P4 samples collected from 5,944 lactations in 1,468 SR and 1,876 SH cows. Pedigree, calving, insemination, culling, and disease data for the cows were extracted from the Swedish cow database maintained by Växa Sverige (Stockholm, Sweden).

\section{Filtering Criteria}

The P4 data were linearly interpolated to estimate the beginning and end of each estrus cycle, where a P4 concentration above $5 \mathrm{ng} / \mathrm{mL}$ was used to define luteal activity. At least 2 consecutive $\mathrm{P} 4$ records above the threshold for luteal activity, a luteal phase length of at least $4 \mathrm{~d}$, and an interovulatory interval greater than 4 $\mathrm{d}$ were required in each estrus cycle.

The HN system is sometimes used to confirm the reproductive status of cows without a full sampling series during the lactation, and therefore a minimum of $10 \mathrm{P} 4$ samples was required per lactation. Furthermore, the first sample had to be taken by 25 DIM and the last sample after 60 DIM. The cow also had to commence luteal activity by 60 DIM, excluding 19 lactations from the analysis. The mean P4 sampling duration was 136 $\pm 73 \mathrm{~d}$ (mean $\pm \mathrm{SD}$ ), with milk samples taken every 2 $\pm 4 \mathrm{~d}$ during the lactation. On average per cow, $43 \pm$ $26 \mathrm{P} 4$ samples (mean $\pm \mathrm{SD}$ ) were taken during the AI period.

Insemination data were corrected for double inseminations (i.e., if the cow was re-inseminated within $6 \mathrm{~d}$ from the first insemination, the later record was used), resulting in exclusion of 511 insemination events. Each insemination was aligned with the $\mathrm{P} 4$ records, and only 1 insemination was accepted per cycle. A maximum of 7 inseminations over a period of $147 \mathrm{~d}$ was permitted during the first 9 estrus cycles. The final data set is summarized in Table 1. 
Table 1. Number of progesterone (P4, ng/mL) samples, inseminations, lactations, and individual Swedish Red (SR) and Swedish Holstein (SH) dairy cows for which data were available in this study

\begin{tabular}{lrrr}
\hline Item & SR and SH & \multicolumn{1}{c}{ SR } & \multicolumn{1}{c}{ SH } \\
\hline P4 records & 330,071 & 131,004 & 199,067 \\
Inseminations & 10,219 & 4,399 & 5,820 \\
1st parity & 3,669 & 1,620 & 2,049 \\
2nd parity & 3,054 & 1,286 & 1,768 \\
>3rd parity & 3,496 & 1,493 & 2,003 \\
Parity & 5,238 & 2,386 & 2,852 \\
1 & 1,903 & 853 & 1,050 \\
2 & 1,542 & 705 & 837 \\
$\geq 3$ & 1,793 & 828 & 965 \\
Cows & 3,304 & 1,457 & 1,847 \\
\hline
\end{tabular}

\section{Trait Definitions}

Pregnancy loss traits were defined based on the P4 profiles, where an insemination was considered unsuccessful if a cow presented at least 2 consecutive $\mathrm{P} 4$ samples below the threshold of luteal activity during gestation. The losses were categorized as early embryonic loss (1-24 d after insemination), late embryonic loss (25-41 d after insemination), fetal loss (42 d after insemination until calving), and total pregnancy loss (d 1 after insemination until calving). Fertilization failures (defined by either absence of onset of luteal phase, or onset of luteal phase followed by $\mathrm{P} 4$ concentrations below the threshold value for luteal activity at some time between 1 and $14 \mathrm{~d}$ after insemination) were also included as total pregnancy loss, because these events still represent failure of an insemination, although not a pregnancy loss per se. Overall, $413(\sim 4 \%)$ of inseminations were unsuccessful due to fertility failure, in 144 $\mathrm{SR}$ and $269 \mathrm{SH}$ cows. The result of each insemination was confirmed using new insemination events, disease, culling, and calving data, and 319 insemination records lacking such information were removed. If a cow was culled due to reproductive failure during gestation, the pregnancy outcome was included in all pregnancy loss traits. However, if a cow was culled due to nonfertilityrelated causes, the result was included under the respective pregnancy loss trait associated with the given time of culling but not included in the total pregnancy loss. Within the whole data set, 269 cows were culled, 70 due to fertility failures and 199 due to other causes.

The P4 concentrations in 5 time intervals after insemination were also analyzed. The records with the highest $\mathrm{P} 4$ value at $10 \mathrm{~d}$ (interval $7-13 \mathrm{~d}$ after insemination), $20 \mathrm{~d}$ (interval 17-23 d after insemination), 30 d (interval 27-33 d after insemination), $40 \mathrm{~d}$ (interval 37-43 d after insemination), and $50 \mathrm{~d}$ (interval 47-53 d after insemination) were used.

The classical fertility traits included were interval from calving to first service (CFS), interval from calv- ing to last service (CLS), interval between first and last service (FLS), calving interval (CIN), and number of inseminations per series (NINS). Thresholds were imposed on these traits to handle outliers (mean \pm 2SD), where CFS between 20 and 140 d, CLS between 21 and 217, and FLS of maximum 147 d were allowed, whereas CIN greater than $495 \mathrm{~d}$ was excluded. Last, MY from the first 305 DIM was analyzed in connection with pregnancy losses, with a minimum threshold of $3,358 \mathrm{~kg}$ milk (mean - 2SD). Mean MY in the Swedish HN herds during 2015 to 2019 was $8,352 \pm 2,485 \mathrm{~kg}$ per lactation in SR and 9,316 $\pm 2,721 \mathrm{~kg}$ per lactation in SH. The national average MY in 2019 was $9,910 \mathrm{~kg}$ per lactation and $10,790 \mathrm{~kg}$ per lactation in SR and $\mathrm{SH}$, respectively (Växa Sverige, 2020).

\section{Statistical Analysis}

Data were analyzed using mixed linear models in SAS (version 9.4, SAS Institute Inc., Cary, NC) to estimate least squares means. Model 1 (Equation 1) was used for pregnancy loss traits and $\mathrm{P} 4$ concentrations at certain time points with 1 observation per insemination, and Model 2 (Equation 2) was used for classical fertility traits with 1 observation per lactation. Classical fertility traits were (natural) log-transformed. Heritabilities were estimated based on the variance components estimates from univariate animal models in the DMU software (Madsen and Jensen, 2013) with Model 3 (Equation 3), and the standard errors were computed based on Taylor series of approximation (Madsen and Jensen, 2013; McKinnon Edwards, 2017). Genetic correlations between traits were estimated using bivariate repeatability models. Model 3 was used for pregnancy loss traits, but MY was modeled without the linear regression on 305-d MY, and the classical fertility traits were analyzed without the effect of cycle. Correlations $<0.4$ were considered weak, 0.4 to 0.7 moderate, and $>0.7$ strong. The models were as follows:

$$
\begin{gathered}
y_{i j k l m}=\mu+B_{i}+P_{j}+E_{k}+b_{1} \mathrm{MY}+h y s_{l}+c_{m}+e_{i j k l m} \\
y_{i j l m}=\mu+B_{i}+P_{j}+b_{1} \mathrm{MY}+h y s_{l}+c_{m}+e_{i j l m}, \\
y_{i j k l n}=\mu+ \\
+B_{i}+P_{j}+E_{k}+b_{1} \mathrm{MY}+h y s_{l} \\
+a_{n}+p e_{n}+e_{i j k l n},
\end{gathered}
$$

where $y$ is the trait analyzed; $\mu$ is overall mean; $B_{i}$ is the fixed effect of the $i$ th breed (SR or $\mathrm{SH}) ; P_{j}$ is the fixed effect of the $j$ th parity (lactations grouped as 1,2 , and $\geq 3) ; E_{k}$ is the fixed effect of the $k$ th estrus cycle 
Table 2. Number of inseminations (percentage in parentheses) resulting in reproductive losses in 1,457 Swedish Red (SR) and 1,847 Swedish Holstein (SH) cows, based on in-line milk progesterone samples $(\mathrm{ng} / \mathrm{mL})$

\begin{tabular}{lrrr}
\hline Trait $^{1}$ & SR and SH & SR & \multicolumn{1}{c}{ SH } \\
\hline EEL & $4,827(49.2)$ & $2,026(47.6)$ & $2,801(50.5)$ \\
LEL & $606(12.2)$ & $174(7.8)$ & $432(15.7)$ \\
FL & $448(10.2)$ & $178(8.7)$ & $270(11.7)$ \\
TPL & $6,095(60.8)$ & $2,442(56.5)$ & $3,653(64.1)$ \\
\hline
\end{tabular}

${ }^{1} \mathrm{EEL}=$ early embryonic loss, 1-24 d after AI, fertility failures excluded; LEL = late embryonic loss, 25-41 d after AI; FL = fetal loss, $42 \mathrm{~d}$ after AI until calving; TPL = total pregnancy loss, $1 \mathrm{~d}$ after AI until calving, excluding 199 inseminations from cows culled due to non-fertility-related causes.

number when the insemination took place $(k=1-9)$; $b_{1} \mathrm{MY}$ is the fixed linear regression on 305-d MY with coefficient $b_{1}$; hys $s_{l}$ is the random effect of herd by insemination year and season [with 14 herds, 5 years (2015, 2016, 2017, 2018, and 2019) and 4 seasons (December to February, March to May, June to August, September to November $)]$, and $\sim N\left(\mathbf{0}, \mathbf{I} \sigma_{\text {hys }}^{2}\right)$, where $\mathbf{I}$ is an identity matrix and $\sigma_{\text {hys }}^{2}$ is the random herd-yearseason variance); $c_{m}$ is the random effect of cow $m\left[\mathrm{c}_{m}\right.$ $\sim N\left(\mathbf{0}, \mathbf{I} \sigma_{c}^{2}\right)$, where $\sigma_{c}^{2}$ is the variance of the cow]; and $e$ is a random error term $\left[e \sim N\left(\mathbf{0}, \mathbf{I} \sigma_{e}^{2}\right)\right.$, where $\sigma_{e}^{2}$ is residual variance]. Model 3 also included the random genetic effect of animal $n\left[a_{n} \sim N\left(\mathbf{0}, \mathbf{A} \sigma_{a}^{2}\right)\right.$, where $\mathbf{A}$ is the additive genetic relationship matrix and $\sigma_{a}^{2}$ is the additive genetic variance]; and the permanent environmental effect of animal $n$ to account for repeated inseminations within lactation $\left[p e_{n} \sim N\left(\mathbf{0}, \mathbf{I} \sigma_{p e}^{2}\right)\right.$, where $\sigma_{p e}^{2}$ is the permanent environmental variance]. Model 3 was used across both breeds and within each breed separately (ignoring the breed effect in the model).

\section{RESULTS}

Of the total of 10,219 inseminations used in the analysis, $60.8 \%$ led to a reproductive loss (Table 2). The conception rate [calculated by: (no. pregnancies $\times$ $100) /$ no. AI)] was $48.7 \%$ at $24 \mathrm{~d}$ after AI, $42.8 \%$ at 41 $\mathrm{d}$ after $\mathrm{AI}$, and $38.4 \%$ in total. SH had the highest level of pregnancy losses, regardless of category.

Approximately $45 \%$ of all pregnancies led to early embryonic loss, but there was no difference between the breeds $(P=0.47$; Table 3$)$. SR cows differed from $\mathrm{SH}$ in terms of the remaining pregnancy loss traits. The largest difference was observed in late embryonic loss, which was more than twice as high for SH $(13.3 \%)$ than for SR $(6.1 \%)$.

Primiparous cows were significantly different from multiparous cows in fetal loss $(P<0.001)$, with the most pronounced difference being $4.5 \%$ of pregnancies lost in primiparous cows compared with $13.3 \%$ in cows in parity $\geq 3$. Total pregnancy loss was also less extensive in primiparous cows than in cows in both second parity $(P=0.002)$ and parity $\geq 3(P<0.001)$. However, there were no significant differences $(P>0.05)$ between parities in early or late embryonic loss, and no significant differences between later parities in fetal loss $(P=0.062)$ or total pregnancy loss $(P=0.307)$.

There were significant differences between the breeds in CFS $(76 \pm 0.8 \mathrm{~d}$ in $\mathrm{SR}, 80 \pm 0.7 \mathrm{~d}$ in $\mathrm{SH} ; P<$ $0.001)$, and CLS $(137 \pm 0.9 \mathrm{~d}$ in SR, $140 \pm 0.8 \mathrm{~d}$ in $\mathrm{SH} ; P<0.001)$. The CIN was $414 \pm 1.2 \mathrm{~d}$ in SR and $416 \pm 1.2 \mathrm{~d}$ in SH. The FLS was $61 \mathrm{~d}$ and NINS was approximately 2.9 in both breeds. The CFS, CLS, and CIN were significantly longer in third and later parities than in parity 1 or $2(P<0.02)$.

There was a significant association between $\mathrm{P} 4$ concentration and pregnancy outcome for most of the time intervals studied during gestation (Table 4). The P4 concentrations from around 10 and $20 \mathrm{~d}$ after AI were the only records without an effect on the pregnancy outcome (from $42 \mathrm{~d}$ to calving; $P=0.57$ and $P=$

Table 3. Least squares means $(\%) \pm$ standard error of pregnancy loss traits estimated from in-line milk progesterone concentrations $(\mathrm{ng} / \mathrm{mL})$ in Swedish Red $(\mathrm{SR})$ and Swedish Holstein $(\mathrm{SH})$ cows $^{1}$

\begin{tabular}{cccccc}
\hline Effect & No. of cows & EEL & LEL & FL & TPL \\
\hline Breed & 1,457 & $43.4 \pm 1.5^{\mathrm{a}}$ & $6.1 \pm 1.2^{\mathrm{a}}$ & $7.0 \pm 1.2^{\mathrm{a}}$ & $54.4 \pm 1.4^{\mathrm{a}}$ \\
SR & 1,847 & $44.8 \pm 1.5^{\mathrm{a}}$ & $13.3 \pm 1.1^{\mathrm{b}}$ & $12.3 \pm 1.2^{\mathrm{b}}$ & $60.6 \pm 1.4^{\mathrm{b}}$ \\
SH & & & & \\
Parity & 1,903 & $43.9 \pm 1.5^{\mathrm{a}}$ & $8.5 \pm 1.2^{\mathrm{a}}$ & $4.5 \pm 1.2^{\mathrm{a}}$ & $54.6 \pm 1.4^{\mathrm{a}}$ \\
1 & 1,542 & $44.0 \pm 1.6^{\mathrm{a}}$ & $10.3 \pm 1.3^{\mathrm{a}}$ & $11.2 \pm 1.3^{\mathrm{b}}$ & $58.3 \pm 1.5^{\mathrm{b}}$ \\
2 & 1,793 & $44.5 \pm 1.6^{\mathrm{a}}$ & $10.3 \pm 1.3^{\mathrm{a}}$ & $13.3 \pm 1.3^{\mathrm{b}}$ & $59.5 \pm 1.5^{\mathrm{b}}$ \\
\hline 3 &
\end{tabular}

${ }^{\mathrm{a}, \mathrm{b}}$ Estimates with different superscripts within a column are significantly different $(P \leq 0.05)$.

${ }^{1} \mathrm{EEL}=$ early embryonic loss, 1-24 d after AI; LEL = late embryonic loss, 25-41 d after AI; FL = fetal loss, $42 \mathrm{~d}$ after AI until calving; TPL = total pregnancy loss, $1 \mathrm{~d}$ after AI until calving. 
Table 4. Least squares means $(\%) \pm \mathrm{SE}$ for progesterone concentrations $(\mathrm{ng} / \mathrm{mL})$ in Swedish dairy cattle at $10,20,30,40$, and $50 \mathrm{~d}$ after insemination, which was used to predict reproductive status on 4 occasions after insemination, in pregnant cows and cows with pregnancy loss (nonpregnant) ${ }^{1}$

\begin{tabular}{llcccc}
\hline Interval & Result & \multirow{2}{*}{$1-24 \mathrm{~d}$} & $25-41 \mathrm{~d}$ & $42 \mathrm{~d}$-calving & $1 \mathrm{~d}$-calving \\
\hline $\mathrm{d} 10$ & Nonpregnant & $18.9 \pm 0.19^{\mathrm{a}}$ & $18.8 \pm 0.29^{\mathrm{a}}$ & $19.7 \pm 0.32^{\mathrm{a}}$ & $18.0 \pm 0.20^{\mathrm{a}}$ \\
& Pregnant & $19.7 \pm 0.18^{\mathrm{b}}$ & $20.0 \pm 0.20^{\mathrm{b}}$ & $19.9 \pm 0.21^{\mathrm{a}}$ & $19.7 \pm 0.20^{\mathrm{b}}$ \\
$\mathrm{d} 20$ & Nonpregnant & $20.2 \pm 0.18^{\mathrm{a}}$ & $25.8 \pm 0.11^{\mathrm{a}}$ & $26.3 \pm 0.11^{\mathrm{a}}$ & $20.5 \pm 0.19^{\mathrm{a}}$ \\
& Pregnant & $26.2 \pm 0.18^{\mathrm{b}}$ & $26.4 \pm 0.07^{\mathrm{b}}$ & $26.4 \pm 0.07^{\mathrm{a}}$ & $26.3 \pm 0.19^{\mathrm{b}}$ \\
$\mathrm{d} 30$ & Nonpregnant & & $14.8 \pm 0.22^{\mathrm{a}}$ & $26.0 \pm 0.10^{\mathrm{a}}$ & $15.1 \pm 0.21^{\mathrm{a}}$ \\
& Pregnant & & $26.1 \pm 0.14^{\mathrm{b}}$ & $26.3 \pm 0.06^{\mathrm{b}}$ & $26.3 \pm 0.21^{\mathrm{b}}$ \\
$\mathrm{d} 40$ & Nonpregnant & & $15.6 \pm 0.22^{\mathrm{a}}$ & $25.0 \pm 0.16^{\mathrm{a}}$ & $22.3 \pm 0.18^{\mathrm{a}}$ \\
& Pregnant & & $25.5 \pm 0.14^{\mathrm{b}}$ & $25.4 \pm 0.09^{\mathrm{b}}$ & $25.3 \pm 0.18^{\mathrm{b}}$ \\
$\mathrm{d} 50$ & Nonpregnant & & & $19.0 \pm 0.24^{\mathrm{a}}$ & $18.0 \pm 0.25^{\mathrm{a}}$ \\
& Pregnant & & & $25.6 \pm 0.14^{\mathrm{b}}$ & $25.8 \pm 0.25^{\mathrm{b}}$ \\
\hline
\end{tabular}

$\overline{\mathrm{a}, \mathrm{b}}$ Estimates with different superscripts within a column are significantly different $(P \leq 0.05)$.

${ }^{1} 1-24 \mathrm{~d}=$ indicative of early embryonic loss during the first $24 \mathrm{~d}$ after $\mathrm{AI} ; 25-41 \mathrm{~d}=$ indicative of late embryonic loss during 25-41 d after AI; $42 \mathrm{~d}$-calving = indicative of fetal loss from $42 \mathrm{~d}$ after AI until calving; $1 \mathrm{~d}$-calving $=$ indicative of reproductive loss during the gestation period.

0.33, respectively). Breed-wise comparisons showed several differences in the pregnancy outcome between SR and SH depending on the P4 concentration during gestation, especially during the first few weeks after insemination (Table 5).

Estimated heritability of the pregnancy loss traits ranged from 0.01 to 0.07 (Table 6). The highest heritability estimate for SR was for early embryonic loss (0.04), whereas for SH it was late embryonic loss (0.07). A heritability of 0.00 was estimated for fetal loss in the total data set and in SR cows. The heritability for CFS, CLS, FLS, NINS, and CIN was estimated at 0.04, $0.01,0.02,0.03$, and 0.02 , respectively. Standard error ranged from 0.01 to 0.03 for both pregnancy loss and classical fertility traits.

Early embryonic loss had a strong genetic correlation with FLS, and a moderate correlation with MY, CFS, CLS, and CIN (Table 7). Late embryonic loss was strongly correlated with both CLS and CIN, moderately correlated with FLS and NINS, and weakly correlated with MY and CFS. The standard error ranged from 0.12 to 0.38 . Residual correlation between embryonic loss traits, MY, and CFS was around zero. The other traits showed weak positive residual correlations with embryonic loss. These results indicate that the model used in the analysis was able to describe most of the

Table 5. Least squares means (\%) \pm standard error for progesterone concentrations $(\mathrm{ng} / \mathrm{mL})$ in Swedish Red (SR) and Swedish Holstein (SH) cows at 10,20,30,40, and $50 \mathrm{~d}$ after insemination, which was used to predict reproductive status on 4 occasions after insemination, in pregnant cows and cows with pregnancy loss (nonpregnant)

\begin{tabular}{|c|c|c|c|c|c|c|}
\hline Interval & Result & Breed & $1-24 d^{1}$ & $25-41 d$ & 42d-calving & 1d-calving \\
\hline \multirow{2}{*}{10} & Nonpregnant & $\mathrm{SH}$ & $18.2 \pm 0.21^{\mathrm{b}}$ & $18.1 \pm 0.33^{\mathrm{b}}$ & $19.2 \pm 0.38^{\mathrm{a}}$ & $17.2 \pm 0.22^{\mathrm{b}}$ \\
\hline & Pregnant & SR & $20.2 \pm 0.21^{\mathrm{a}}$ & $20.5 \pm 0.23^{\mathrm{a}}$ & $20.4 \pm 0.24^{\mathrm{a}}$ & $20.2 \pm 0.24^{\mathrm{a}}$ \\
\hline \multirow[t]{3}{*}{20} & \multirow[t]{2}{*}{ Nonpregnant } & SR & $18.6 \pm 0.22^{\mathrm{a}}$ & $25.9 \pm 0.17^{\mathrm{a}}$ & $26.3 \pm 0.16^{\mathrm{a}}$ & $19.1 \pm 0.22^{\mathrm{a}}$ \\
\hline & & $\mathrm{SH}$ & $21.5 \pm 0.20^{\mathrm{b}}$ & $25.7 \pm 0.12^{\mathrm{a}}$ & $26.2 \pm 0.13^{\mathrm{a}}$ & $21.6 \pm 0.21^{\mathrm{b}}$ \\
\hline & Pregnant & SR & $26.6 \pm 0.21^{\mathrm{a}}$ & $26.4 \pm 0.08^{\mathrm{a}}$ & $26.4 \pm 0.08^{\mathrm{a}}$ & $26.6 \pm 0.23^{\mathrm{a}}$ \\
\hline \multirow{2}{*}{30} & \multirow[t]{2}{*}{ Pregnant } & SR & & $26.1 \pm 0.16^{\mathrm{a}}$ & $26.4 \pm 0.07^{\mathrm{a}}$ & $26.3 \pm 0.25^{\mathrm{a}}$ \\
\hline & & SH & & $26.1 \pm 0.16^{\mathrm{a}}$ & $26.3 \pm 0.07^{\mathrm{a}}$ & $26.2 \pm 0.25^{\mathrm{a}}$ \\
\hline \multirow[t]{4}{*}{40} & \multirow[t]{2}{*}{ Nonpregnant } & SR & & $15.6 \pm 0.35^{\mathrm{a}}$ & $24.6 \pm 0.23^{\mathrm{a}}$ & $22.1 \pm 0.22^{\mathrm{a}}$ \\
\hline & & $\mathrm{SH}$ & & $15.5 \pm 0.25^{\mathrm{a}}$ & $25.1 \pm 0.19^{\mathrm{a}}$ & $22.4 \pm 0.20^{a}$ \\
\hline & \multirow{2}{*}{ Pregnant } & SR & & $25.6 \pm 0.16^{\mathrm{a}}$ & $25.5 \pm 0.10^{\mathrm{a}}$ & $25.5 \pm 0.22^{\mathrm{a}}$ \\
\hline & & $\mathrm{SH}$ & & $25.4 \pm 0.16^{\mathrm{a}}$ & $25.3 \pm 0.10^{\mathrm{b}}$ & $25.2 \pm 0.21^{\mathrm{a}}$ \\
\hline
\end{tabular}

\footnotetext{
${ }^{\mathrm{a}, \mathrm{b}}$ Estimates with different superscripts within a column are significantly different $(P \leq 0.05)$.

${ }^{1} 1-24 \mathrm{~d}=$ indicative of early embryonic loss during the first $24 \mathrm{~d}$ after AI; $25-41 \mathrm{~d}=$ indicative of late embryonic loss during $25-41 \mathrm{~d}$ after AI; $42 \mathrm{~d}$-calving = indicative of fetal loss from $42 \mathrm{~d}$ after AI until calving; 1d-calving = indicative of reproductive loss during the gestation period.
} 
Table 6. Estimated heritability $\left(\mathrm{h}^{2}\right)$, SE, and additive genetic variance $\left(\sigma_{a}^{2}\right)$ of pregnancy loss traits in Swedish Red (SR) and Swedish Holstein (SH) dairy cows

\begin{tabular}{|c|c|c|c|c|c|c|c|c|c|}
\hline \multirow[b]{2}{*}{ Trait $^{1}$} & \multicolumn{3}{|c|}{$\mathrm{SR}$ and $\mathrm{SH}$} & \multicolumn{3}{|c|}{ SR } & \multicolumn{3}{|c|}{$\mathrm{SH}$} \\
\hline & $h^{2}$ & $\mathrm{SE}$ & $\sigma_{a}^{2}$ & $h^{2}$ & $\mathrm{SE}$ & $\sigma_{a}^{2}$ & $h^{2}$ & $\mathrm{SE}$ & $\sigma_{a}^{2}$ \\
\hline EEL & 0.03 & 0.01 & 0.007 & 0.04 & 0.02 & 0.01 & 0.02 & 0.02 & 0.006 \\
\hline LEL & 0.06 & 0.02 & 0.007 & 0.03 & 0.03 & 0.002 & 0.07 & 0.03 & 0.009 \\
\hline FL & 0.00 & 0.02 & 0.00 & 0.00 & 0.02 & 0.00 & 0.02 & 0.02 & 0.002 \\
\hline TPL & 0.02 & 0.01 & 0.004 & 0.03 & 0.02 & 0.007 & 0.01 & 0.01 & 0.001 \\
\hline
\end{tabular}

${ }^{1} \mathrm{EEL}=$ early embryonic loss, 1-24 d after AI; LEL = late embryonic loss, 25-41 d after AI; FL = fetal loss, $42 \mathrm{~d}$ after AI until calving; TPL = total pregnancy loss, $1 \mathrm{~d}$ after AI until calving.

genetic and environmental components of the correlations.

\section{DISCUSSION}

Impaired fertility is a major concern in the dairy industry. One crucial aspect of fertility is the outcome of pregnancy, and reports of low calving rates indicate high reproductive loss during gestation. It is therefore important to determine genetic variation in reproductive loss and genetically improve the ability to maintain pregnancy to full term, thus increasing favorable pregnancy outcomes. In this study, we evaluated the extent of reproductive loss traits and estimated genetic parameters for these using automatically sampled milk P4 records for Swedish dairy cows in 14 herds. This is the first study to use information on reproductive loss during gestation obtained from a large number of animals of the 2 most common dairy breeds kept in Swedish conditions, which also permitted genetic analysis of the data set.

\section{Genetic Parameters of Pregnancy Loss Traits}

The heritability estimates for pregnancy loss traits in this study were of the same order of magnitude as previously reported for classical fertility traits $(0.01-0.07$,
Muuttoranta et al., 2019; NAV, 2020). Estimates of genetic parameters for pregnancy loss traits are scarce in the literature, indicating a need for further research. To the best of our knowledge, only van Binsbergen et al. (2019) have reported estimates for a trait related to reproductive losses derived from $\mathrm{P} 4$ data. They estimated the heritability for late embryonic loss to be $0.04( \pm 0.04)$, which is comparable to our own results. The low estimates obtained in this study was probably mainly due to large environmental variance in pregnancy loss traits.

Bamber et al. (2009) reported an estimated heritability of $0.16( \pm 0.11)$ for late embryonic loss, but their trait was based on pregnancy diagnosis using ultrasound examinations and not on $\mathrm{P} 4$ profile recordings. Their estimate is relatively high for a fertility trait, but is associated with a larger standard error, indicating lower precision. Further, they speculated that their results could be due to data recording on few cows in controlled environments by skilled technicians, and that field data would likely yield much lower estimates (Bamber et al., 2009).

Other studies have also used ultrasound diagnostics; for example, Carthy et al. $(2015,2016)$ estimated heritability to be 0.02 for reproductive loss from 21 d after AI until end of gestation. This is comparable with our heritability estimates for fetal loss in SH cows

Table 7. Estimated genetic $\left(r_{\mathrm{g}}\right)$ and residual $\left(\mathrm{r}_{\mathrm{e}}\right)$ correlation, with standard error (subscript), between pregnancy loss traits, milk yield, and classical fertility traits in Swedish Red and Swedish Holstein cows ${ }^{1}$

\begin{tabular}{|c|c|c|c|c|c|c|}
\hline Trait $^{2}$ & MY & CFS & CLS & FLS & CIN & NINS $^{3}$ \\
\hline $\begin{array}{l}\mathrm{r}_{\mathrm{g}} \\
\mathrm{EEL} \\
\mathrm{LEL}\end{array}$ & $\begin{array}{l}0.52_{0.20} \\
0.39_{0.19}\end{array}$ & $\begin{array}{r}-0.46_{0.28} \\
0.35_{0.28}\end{array}$ & $\begin{array}{l}0.45_{0.29} \\
0.92_{0.15}\end{array}$ & $\begin{array}{l}0.85_{0.16} \\
0.51_{0.32}\end{array}$ & $\begin{array}{l}0.43_{0.38} \\
0.91_{0.12}\end{array}$ & $\begin{array}{l}\mathrm{NC} \\
0.52_{0.30}\end{array}$ \\
\hline $\begin{array}{l}\mathrm{r}_{\mathrm{e}} \\
\text { EEL } \\
\text { LEL }\end{array}$ & $\begin{array}{l}-0.02_{0.01} \\
-0.01_{0.02}\end{array}$ & $\begin{array}{l}0.00_{0.01} \\
0.03_{0.02}\end{array}$ & $\begin{array}{l}0.38_{0.01} \\
0.38_{0.01}\end{array}$ & $\begin{array}{l}0.40_{0.01} \\
0.32_{0.02}\end{array}$ & $\begin{array}{l}0.38_{0.01} \\
0.48_{0.02}\end{array}$ & $\begin{array}{l}\mathrm{NC} \\
0.36_{0.02}\end{array}$ \\
\hline
\end{tabular}

${ }^{1} \mathrm{MY}=$ milk yield from 305-d lactation, $\mathrm{kg}$; CFS = interval from calving to first service, $\mathrm{d}$; CLS = interval from calving to last service, $d$; FLS = interval from first to last service, $d$; CIN = calving interval, $d$; NINS = number of inseminations per AI-period.

${ }^{2} \mathrm{EEL}=$ early embryonic loss, 1-24 d after AI; LEL = late embryonic loss, 25-41 d after AI.

${ }^{3} \mathrm{NC}=$ not converged. 
and reproductive losses in total. However, we estimated zero heritability for fetal loss in the full data set and in SR cows. These results were most likely due to small sample size, as we only had access to 448 cases of fetal loss in total. Thus, further studies on larger data sets are necessary to obtain reliable estimates for this trait.

Embryonic losses were moderately genetically correlated with MY (0.39-0.52) in this study, which is in agreement with reports of higher number of AI required per successful pregnancy in high-yielding dairy cattle (Nyman et al., 2018). However, van Binsbergen et al. (2019) reported a much lower genetic correlation between late embryonic loss and MY $(-0.02 \pm 0.05)$, and attributed this to the nature and precision of $\mathrm{P} 4$ recordings. In comparison, classical fertility traits are calculated from calving and insemination data, and therefore risk being biased due to recording errors and management practices that can affect the perceived fertility of the cow (van Binsbergen et al., 2019). Carthy et al. (2016) found reproductive loss to be genetically correlated with fat content $(-0.17 \pm 0.099)$, fat-protein ratio $(-0.22 \pm 0.103)$, and SCS (0.32 \pm 0.119$)$.

A study by van Binsbergen et al. (2019) found a lower genetic correlation between late embryonic loss and CIN $(0.34 \pm 0.08)$ than observed in this study $(0.91 \pm 0.12)$. We also found stronger associations between late embryonic loss and FLS $(0.51 \pm 0.32)$ and NINS $(0.52 \pm 0.30)$ than van Binsbergen et al. (2019) $(0.31 \pm 0.13$ and $0.37 \pm 0.11$, respectively), although our estimates had high standard error. Differences in recording practices, management, and data filtering could have contributed to the differences in results. Genetic correlations between late embryonic loss and CFS were of similar magnitude in the 2 studies. These results indicate that cows with impaired fertility have difficulties conceiving and in supporting early embryo development and survival.

The low number of cases on fetal loss in our data set influenced the analysis, as genetic correlations were not estimable for any of the bivariate analyses associated with fetal loss. However, estimates from Carthy et al. (2015) suggest that reproductive losses from $21 \mathrm{~d}$ after AI are strongly genetically correlated with CIN (0.8 \pm 0.097), moderately correlated with CFS $(0.55 \pm 0.165)$ and days open $(0.44 \pm 0.141)$, and weakly correlated with NINS $(0.33 \pm 0.183)$.

\section{Descriptive Evaluation of Pregnancy Loss}

Our estimates for early embryonic loss $(\sim 45 \%)$ are in line with those in Bruinjé et al. (2017) who reported $59 \%$ pregnancy losses within $30 \mathrm{~d}$ of insemination in Canadian cows. Both are much higher than the $29 \%$ estimated by Nyman et al. (2018) for Swedish SH and
SR. However, these differences are probably explained by different sampling methods and filtering criteria imposed on the data. Nyman et al. (2018) estimated pregnancy losses in Swedish dairy cows based on manually sampled $\mathrm{P} 4$ records collected on the day of insemination and at 10 and $21 \mathrm{~d}$ after each insemination, until the cows were confirmed pregnant. Continuous sampling through the lactation was used by Bruinjé et al. (2017) and in the present study. Furthermore, the sampling frequency is determined by the $\mathrm{HN}$ biomodel based on the P4 profile, and on cow- and lactation-specific characteristics (Friggens and Chagunda, 2005; Bruinjé and Ambrose, 2019). Although using more data points to assess the result of insemination provides a more precise description of the reproductive status of the cow through the lactation, the fertility outcome is still affected by farm management decisions (e.g., voluntary waiting periods, preferential treatment of high-yielding cows) and does not depend solely on the biomodel.

Bruinjé et al. (2017) estimated that a further 12.9\% of pregnancies were lost between 31 and $55 \mathrm{~d}$ after insemination, which is similar to the late embryonic losses reported by Nyman et al. (2018), van Binsbergen et al. (2019), and this study. In total, Bruinjé et al. (2017) found that 28\% of inseminations resulted in pregnant cows at $55 \mathrm{~d}$ after insemination, which is comparable to our estimates. Although the majority of reproductive losses in dairy cattle happen during the early embryonic stage of the pregnancy (observed as cows returning to heat), losses in later gestation have higher negative economic effect on production due to the cost of keeping unproductive animals in the herd (Santos et al., 2004; Diskin et al., 2012).

Nyman et al. (2018) reported significantly less total pregnancy loss in SR than SH (62.4 and 67.9\%, respectively). This is in line with our own findings, but we observed significant breed differences for all pregnancy loss traits except early embryonic loss. Similarly to Nyman et al. (2018), we observed a significant increase in fetal loss and total pregnancy loss with increasing parity.

We observed a stable level of early embryonic loss, regardless of age of the cow, but Bruinjé et al. (2017) observed an effect of parity, with an increase of $12.6 \%$ in non-pregnant rate from primiparous to secondparity cows. They also reported an $11 \%$ increase in late embryonic loss from first to second parity. Although these results are interesting, their study was based on a smaller data set and they do not specify whether their results are statistically significant, possibly because their main focus was on changes in $\mathrm{P} 4$ concentrations in relation to insemination success.

We detected an increase in number of inseminations used in HN herds (2.2) compared with the average (1.8) 
reported by Växa Sverige (2020) for non-HN herds in Sweden. Increased number of data points during estrus (Bruinjé et al., 2019; Bruinjé and Ambrose, 2019), estimated likelihood of insemination success for a given estrus (Blavy et al., 2018; Bruinjé and Ambrose, 2019), and a stronger emphasis on following the recommendations for timing of insemination identified by the $\mathrm{HN}$ system could possibly decrease the number of inseminations outside the optimal time for conception in $\mathrm{HN}$ herds.

\section{P4 Concentration Indicative of Reproductive Loss}

An abnormal endocrine pattern, monitored as fluctuations in $\mathrm{P} 4$, and negative energy balance have a negative effect on oocyte quality, follicular development, and uterine environment, and thus compromise early embryo survival (Diskin et al., 2012; Bruinjé et al., 2017; Blavy et al., 2018). For instance, the P4 concentration in certain intervals after insemination has been found to significantly affect the outcome of insemination. Swedish dairy cows suffering pregnancy losses from late embryonic stage onwards had significantly higher P4 concentrations on the day of insemination than cows that calved successfully (Båge, 2003; Nyman et al., 2018). It would be interesting to study this using continuously sampled data from Sweden, but the sampling frequency in HN herds is based on the biomodel, which meant that fewer than $15 \%$ of inseminations in our data set could be connected to a P4 sample on the day of service.

We were able to investigate the effect of $\mathrm{P} 4$ concentration on pregnancy outcome during 5 intervals from 10 to $50 \mathrm{~d}$ after insemination. Similarly to Bruinjé et al. (2017) and Nyman et al. (2018), we found significantly lower P4 concentration during the intervals in nonpregnant compared with pregnant cows from late embryonic stage onwards. This indicates the importance of continuously high $\mathrm{P} 4$ concentrations during gestation to support development of the embryo and fetus. We also observed several breed differences in $\mathrm{P} 4$ concentration, depending on the outcome of the insemination. These indicate reproductive physiological differences between $\mathrm{SR}$ and $\mathrm{SH}$, which should be considered when setting up $\mathrm{HN}$ and refining the system.

\section{Application in Future Breeding Strategies}

Endocrine-derived traits are promising for describing reproductive loss in dairy cattle (Bruinjé et al., 2017, 2019; van Binsbergen et al., 2019). One of the main issues associated with traits derived from $\mathrm{P} 4$ data is that these data are not available in the national cow database. Another concern is the limited number of $\mathrm{HN}$ units in use in the Nordic countries today, currently around 40 herds, which is primarily due to the high running costs of the system. The low number of animal records currently available is most likely not enough to benefit selection or genetic evaluation based on these traits (Tenghe et al., 2016, 2018; van Binsbergen et al., 2019). However, the collective HN data could serve as a reference population for genomic evaluation of reproductive loss (Tenghe et al., 2016, 2018; Tarekegn et al., 2019).

The strong associations between traits for embryonic loss and FLS (0.82), CLS (0.92), and CIN (0.91) suggest that these traits express much of the same variation. This is encouraging, because these classical fertility traits are already included in Nordic breeding programs (NAV, 2020). The current fertility index in the Nordic programs is mainly focused on the genetic ability of dairy cows to resume cyclicity after calving, show estrus, and become pregnant after insemination (NAV, 2020). Although there are numerous studies relating to the first 2 aspects of the fertility index, more research is required on the ability of high-yielding cows to maintain their pregnancy to full term.

Use of biosensor technology is likely to increase on farms with the move toward more automated production systems. Future studies should explore how biosensor data can be used efficiently to improve genetic and genomic evaluations.

\section{CONCLUSIONS}

Analysis of in-line milk progesterone records revealed that approximately $45 \%$ of all inseminations resulted in early pregnancy loss, $12 \%$ in late embryonic loss, and $10 \%$ in fetal loss. SR cows had significantly lower pregnancy loss during late embryonic stage, fetal stage, and in total, and had better fertility than SH cows. Diagnosing reproductive loss early in gestation could reduce losses in production, decrease the risk of premature culling, and increase herd profitability. The heritability estimates obtained for pregnancy loss traits were low and of the same order of magnitude as those for classical fertility traits. Embryonic loss showed moderate to strong genetic correlations with milk production and several classical fertility traits. These results could be valuable for determining genetic variation in reproductive loss and its potential usefulness as an alternative fertility trait in genetic or genomic evaluations. Further studies are required for better predictive estimates of these novel traits, to modernize breeding strategies and exploit modern biosensor technologies for genetic improvements of dairy cattle fertility. 


\section{ACKNOWLEDGMENTS}

This project was funded by the Swedish Farmers' Foundation for Agricultural Research (project ID O-1520-587). We gratefully acknowledge the herd owners in Sweden who contributed data from their herds, and Lattec I/S for providing the in-line progesterone records. We also acknowledge Växa Sverige for providing us with data from the Swedish cow database. The authors state no conflicts of interest.

\section{REFERENCES}

Båge, R. 2003. Conception rates after AI in Swedish red and white dairy heifers: Relationship with progesterone concentrations at AI. Reprod. Domest. Anim. 38:199-203. https://doi.org/10.1046/ j.1439-0531.2003.00426.x.

Båge, R., H. Gustafsson, B. Larsson, M. Forsberg, and H. RodríguezMartínez. 2002. Repeat breeding in dairy heifers: Follicular dynamics and oestrous cycle characteristics in relation to sexual hormone patterns. Theriogenology 57:2257-2269. https://doi.org/10 .1016/S0093-691X(02)00840-3.

Bamber, R. L., G. E. Shook, M. C. Wiltbank, J. E. P. Santos, and P. M. Fricke. 2009. Genetic parameters for anovulation and pregnancy loss in dairy cattle. J. Dairy Sci. 92:5739-5753. https://doi .org/10.3168/jds.2009-2226.

Blavy, P., N. C. Friggens, K. R. Nielsen, J. M. Christensen, and M. Derks. 2018. Estimating probability of insemination success using milk progesterone measurements. J. Dairy Sci. 101:1648-1660. https://doi.org/10.3168/jds.2016-12453.

Bruinjé, T. C., and D. J. Ambrose. 2019. Technical note: Validation of an automated in-line milk progesterone analysis system to diagnose pregnancy in dairy cattle. J. Dairy Sci. 102:3615-3621. https: //doi.org/10.3168/jds.2018-15692.

Bruinjé, T. C., M. G. Colazo, E. S. Ribeiro, M. Gobikrushanth, and D. J. Ambrose. 2019. Using in-line milk progesterone data to characterize parameters of luteal activity and their association with fertility in Holstein cows. J. Dairy Sci. 102:780-798. https://doi .org/10.3168/jds.2018-14654.

Bruinjé, T. C., M. Gobikrushanth, M. G. Colazo, and D. J. Ambrose. 2017. Dynamics of pre- and post-insemination progesterone profiles and insemination outcomes determined by an in-line milk analysis system in primiparous and multiparous Canadian Holstein cows. Theriogenology 102:147-153. https://doi.org/10.1016/ j.theriogenology.2017.05.024.

Carthy, T. R., D. P. Ryan, A. M. Fitzgerald, R. D. Evans, and D. P. Berry. 2015. Genetic parameters of ovarian and uterine reproductive traits in dairy cows. J. Dairy Sci. 98:4095-4106. https://doi .org/10.3168/jds.2014-8924.

Carthy, T. R., D. P. Ryan, A. M. Fitzgerald, R. D. Evans, and D. P. Berry. 2016. Genetic relationships between detailed reproductive traits and performance traits in Holstein-Friesian dairy cattle. J. Dairy Sci. 99:1286-1297. https://doi.org/10.3168/jds.2015-9825.

Committee on Bovine Reproductive Nomenclature. 1972. Recommendations for standardizing bovine reproductive terms. Cornell Vet. $62: 216-237$.

DeLaval International. 2011. Herd Navigator and reproduction management. Accessed Dec. 8, 2020. http://www.milkproduction.com/ Documents/HN_Reproduktion\%20management_110328.pdf.

Diskin, M. G., M. H. Parr, and D. G. Morris. 2011. Embryo death in cattle: An update. Reprod. Fertil. Dev. 24:244-251. https://doi .org/10.1071/RD11914.
Ealy, A. D., and Z. K. Seekford. 2019. Symposium review: Predicting pregnancy loss in dairy cattle. J. Dairy Sci. 102:11798-11804. https://doi.org/10.3168/jds.2019-17176.

Friggens, N. C., and M. G. G. Chagunda. 2005. Prediction of the reproductive status of cattle on the basis of milk progesterone measures: Model description. Theriogenology 64:155-190. https:// doi.org/10.1016/j.theriogenology.2004.11.014.

Madsen, P., and J. Jensen. 2013. A User's Guide to DMU: A Package for Analysing Multivariate Mixed models. Version 6, release 5.2. Department of Genetics and Biotechnology, Faculty of Life Sciences, University of Aarhus, Research Centre Foulum, Tjele, Denmark.

McKinnon Edwards, S. 2017. Standard errors of heritability estimates. Accessed Mar. 12, 2020. http://www.iysik.com/dmu/heritabilities.

Muuttoranta, K., A.-M. Tyrisevä, E. A. Mäntysaari, J. Pösö, G. Pedersen Aamand, and M. H. Lidauer. 2019. Genetic parameters for female fertility in Nordic Holstein and Red Cattle dairy breeds. J. Dairy Sci. 102:8184-8196. https://doi.org/10.3168/jds.2018-15858.

NAV (Nordic Cattle Genetic Evaluation). 2020. NAV routine genetic evaluation of Dairy Cattle - Data and genetic models. Accessed Dec. 8, 2020. https://www.nordicebv.info/wp-content/uploads/ 2020/12/NAV-routine-genetic-evaluation_CORRECmetabolic -efficiency-01102020.pdf.

Nyman, S., H. Gustafsson, and B. Berglund. 2018. Extent and pattern of pregnancy losses and progesterone levels during gestation in Swedish Red and Swedish Holstein dairy cows. Acta Vet. Scand. 60:68. https://doi.org/10.1186/s13028-018-0420-6.

Santos, J. E. P., W. W. Thatcher, R. C. Chebel, R. L. A. Cerri, and K. N. Galvão. 2004. The effect of embryonic death rates in cattle on the efficacy of estrus synchronization programs. Anim. Reprod. Sci. 82-83:513-535. https://doi.org/10.1016/j.anireprosci.2004.04 .015 .

Tarekegn, G. M., P. Gullstrand, E. Strandberg, R. Båge, E. RiusVilarrasa, J. M. Christensen, and B. Berglund. 2019. Genetic parameters of endocrine fertility traits based on in-line milk progesterone profiles in Swedish Red and Holstein dairy cows. J. Dairy Sci. 102:11207-11216. https://doi.org/10.3168/jds.2019-16691.

Tenghe, A. M. M., B. Berglund, E. Wall, R. F. Veerkamp, and D. J. de Koning. 2016. Opportunities for genomic prediction for fertility using endocrine and classical fertility traits in dairy cattle. J. Anim. Sci. 94:3645-3654. https://doi.org/10.2527/jas.2016-0555.

Tenghe, A. M. M., A. C. Bouwman, B. Berglund, D. J. de Koning, and R. F. Veerkamp. 2018. Improving accuracy of bulls' predicted genomic breeding values for fertility using daughters' milk progesterone profiles. J. Dairy Sci. 101:5177-5193. https://doi.org/10 $.3168 /$ jds.2016-12304.

Tenghe, A. M. M., A. C. Bouwman, B. Berglund, E. Strandberg, J. Y. Blom, and R. F. Veerkamp. 2015. Estimating genetic parameters for fertility in dairy cows from in-line milk progesterone profiles. J. Dairy Sci. 98:5763-5773. https://doi.org/10.3168/jds.2014-8732.

van Binsbergen, R., A. C. Bouwman, and R. F. Veerkamp. 2019. Genetic parameters for atypical reproductive patterns in dairy cows estimated from in-line milk progesterone profiles. J. Dairy Sci. 102:11104-11115. https://doi.org/10.3168/jds.2019-16348.

Växa Sverige. 2020. Cattle statistics. Accessed Mar. 13, 2020. https: //www.vxa.se/globalassets/dokument/statistik/husdjursstatistik -2020.pdf.

\section{ORCIDS}

P. Ask-Gullstrand ๑ https://orcid.org/0000-0002-7450-8208

E. Strandberg ๑ https://orcid.org/0000-0001-5154-8146

R. Båge @ https://orcid.org/0000-0003-1413-6913

J. M. Christensen @ https://orcid.org/0000-0002-6503-5066 